\title{
PROGRAM KEMITRAAN MASYARAKAT (PKM) SEKOLAH DASAR DI DESA PASSO KECAMATAN KAKAS BARAT KABUPATEN MINAHASA
}

\author{
Sandra Rakian \\ Universitas Negeri Manado \\ sandrarakian@unima.ac.id
}

\begin{abstract}
Abstrak
Program Kegiatan Pengabdian Kepada Masyarakat yang diselenggarakan oleh LPPM UNIMA, yang bertajuk "PKM Sekolah Dasar di Desa Passo Kecamatan Kakas Barat Kecamatan Kakas Barat Kabupaten Minahasa" ini, akan melaksanakan dua kegiatan utama, yaitu kegiatan pelatihan bahasa Toulour dan kegiatan penataan perpustakaan sekolah. Kegiatan-kegiatan ini bertujuan untuk mengatasi masalah belum terealisasinya pembelajaran bahasa Toulour di sekolah-sekolah oleh karena belum modul ajar yang menjadi acuan mengajar, yang menyebabakan sekolah belum dapat berperan untuk melestarikan bahasa Toulour yang terancam punah. Penataan perpustakaan, sekaligus meningkatkan minat baca para siswa. Dua Sekolah Dasar yang dijadikan mitra kegiatan pengabdian ini adalah SD INPRES PASSO dan SD Khatolik Santa Theresia Passo.

Metode yang digunakan dalam pelatihan ini adalah metode eklektik, yaitu metode campuran dari beberapa metode pengajaran bahasa, seperti metode terjemahan, metode langsung, metode mimikri dan metode-metode pengajaran yang umum, seperti metode ceramah, tanya-jawab dan penugasan. Semua metode ini diterapkan berbasis berbasis pendekatan komunikatif, pendekatan kontekstual dan pendekatan Whole language (integrasi semua keterampilan berbahasa). Untuk kegiatan penataan perpustakaan dilakukan dengan melakukan sharing antara tim pelaksana dengan pihak mitra, dalam hal ini kepala sekolah dan guru-guru di kedua sekolah mitra dalam menentukan butirbutir kegiatan yang akan dilaksanakan. Kegiatan penataan perpustakaan meliputi pengadaan/penambahan koleksi buku dan pengaturan ruang perpustakaan menjadi rapih, bersih dan indah.
\end{abstract}

Kata-Kata Kunci: kepunahan Bahasa, Pelestariaan Bahasa, Pemberdayaan Perpustakaan

\section{PENDAHULUAN}

Sekolah dasar adalah lembaga

pendidikan yang memegang peranan sangat

penting dalam meletakkan dasar-dasar bagi

pembangunan manusia Indonesia seutuhnya,

sebagaimana yang menjadi tujuan nasional,

yaitu manusia yang beriman dan bertaqwa

kepada Tuhan Yang Maha Esa, bermorl dan

berkarakter Pancasila serta berwawasan

ilmu pengetahuan dan teknologi. Karena itu

Sekolah Dasar perlu mendapatkan perhatian dari semua pihak, agar dapat menjalankan fungsinya sebagaimana yang diharapkan.

Pada hakekatnya banyak Sekolah Dasar, apalagi yang ada di pedesaan belum dapat menjalankan fungsinya secara maksimal oleh karena terdapat banyak permasalahan yang harus dihadapi dan diselesaikan oleh sekolah-sekolah tersebut. Permasalahan yang ada antara lain sumber daya manusia, dalam hal ini guru yang tidak memadai dari segi kuantitas maupun 
kualitas, sarana dan prasarana penunjang aktivitas belajar mengajar yang tidak lengkap, dan masalah-masalah lain yang terkait dengan penyelenggaraan pendidikan, yang kesemuanya bila diukur berdasarkan Standar Nasional Pendidikan masih sangat jauh dari apa yang seharusnya ada.

Permasalah-permasalahan seperti ini juga dihadapi oleh sekolah-sekolah Dasar yang ada di Desa Passo. Desa Passo adalah desa yang terdiri dari 9 Jaga di Kecamatan Kakas Barat Kabupaten Minahasa. Desa Passo terdapat beberapa sekolah, mulai dari TK, TK di Passo ada 4 yaitu TK GMIM, TK Blessing, TK Gloria dan TK Josua. Sekolah Dasar, SD di Passo ada 3 yaitu SDN Inpres, SD GMIM dan SD Katolik St. Theresia. SMP, di Passo SMP Negeri 6. Dan yang termasuk sekolah Mitra dalam pengabdian yang akan dilakukan yaitu SD Inpres dan SD Katolik St. Theresia Passo.

SDN Inpres adalah sekolah yang didirikan pada Tahun 1974. Berdiri diatas tanah seluas $4265 \mathrm{~m}^{\wedge} 2$. Jumlah guru 7 Orang, 4 orang PNS dan 3 orang honorer diantaranya telah memiliki kualifikasi S 1 dan berpredikat guru profesional. Jumlah siswa 63 murid. Secara fisik sekolah ini perlu penataan dan pembenahan. SD Katolik St. Theresia adalah sekolah yang didirikan pada tanggal 1 Agustus 1956, luas tanah $3500 \mathrm{~m}^{\wedge} 2$. Memiliki 7 orang Guru 1 Orang PNS dan I guru yayasan 5 orang sebagai guru honorer. Jumlah murid 87 orang murid. Secara fisik masih memerlukan penataan dan pembenahan sebagaimana SDN Inpres.

SD Inpres dan SD Katolik St. Theresya masing-masing memiliki satu ruangan perpustakaan, namun tidak dimanfaatkan dengan baik. Ini nampak dari keadaan ruangan yang tidak tertata, jumlah buku yang sangat sedikit dan tidak aktual, yang membuat anak-anak tidak tertarik untuk memanfaatkan perpustakaan. Perpustakaan di dua sekolah masih perlu ditata kembali untuk menambah minat siswa didalam membaca buku, karena dengan keadaan seperti sekarang ini mengakibatkan perpustakaan jarang digunakan oleh para siswa. Mungkin para siswa jenuh karena tidak ada hal yang baru diperpustakaan, termasuk koleksi buku yang ada. Hal ini menyebabkan frekuensi kunjungan keperpustakaan ataupun jumlah anak berkunjung keperpustakaan hanya berkisar $10-15 \%$.

Selain masalah perpustakaan, masalah prioritas yang perlu diatasi oleh sekolah adalah belum terealisasinya pembelajaran bahasa Tolour yang telah diprogramkan selama beberapa tahun terakhir ini. Guru-guru bersama orang tua pada dasarnya prihatin dengan masalah bahasa Tolour yang terancam punah. Kebutulan juga saya dipercayakan di SDN Inpres Passo sebagai Ketua Komite Sekolah, 
masalah ini menjadi salah satu program untuk melestarikan bahasa Daerah. Oleh karena itu sekolah-sekolah ini hendak menyatakan kepeduliannya dengan memprogramkan pembelajaran bahasa Toulour sebagai bahasa Daerah masyarakat Minahasa yang disadari sudah tidak lagi dimengerti apalagi digunakan oleh anakanaka usia Sekolah Dasar di desa Passo Kecamatan Kakas Barat. Jika hal ini dibiarkan terus berlanjut maka bahasa Toulour secara perlahan-lahan akan punah. Gunawan (2007:17) megemukakan bahawa tendensi kepunahan ini disebabkan antara lain oleh karena belum ada upaya yang serius untuk mengatasi permasalahan ini. Di sisi lain generasi tua, para orang tua juga tidak lagi berupaya menggunakan bahasa ini dalam komunikasi dalam komunikasi dengan anak-anak sehari-hari. Faktor lain juga adalah kurangnya keterlibatan para pakar bahasa dan pemangku adat/budaya dalam pelestarian bahasa Toulour. Chaer dan Agustina (2010/145) mengemukakan juga penyebab lainnya, yaitu penggunaan bahasa Melayu yang lebih dominan dan dipandang lebih prestiius karena berfungsi sebagai bahasa Lingua franca atau bahasa penghubung berbagai etnis yang ada di Sulawesi Utara.

Keinginan untuk mengajarkan bahasa Toulour secara resmi sebagai mata pelajaran muatan lokal disekolah-sekolah ini sampai saat ini belum dapat diwujudkan. Alasan yang paling utama belum adanya buku panduan ataupun modul ajar bahasa Toulour yang dapat dijadikan acuan mengajar oleh guru-guru, masalah lain juga adalah karena belum tersedianya guru yang mampu mengajar bahasa Toulour. Bahasa Toulour memang berpotensi akan punah bila tidak ada kerja sama yang serius antara pemerintah, masyarakat dan para pakar bahasa Toulour. Keseriusan pemerintah untuk memasukkan bahasa Toulour sebagai mata pelajaran wajib/muatan lokal sangat diperlukan. Memberikan pelatihan-pelatihan selagi belum ada guru-guru yang dapat mengajarkan bahasa ini secara berkelanjutan di sekolah-sekolah juga adalah alternatif kebijakan yang dapat dilaksanakan. Dengan mengajarkan bahasa Toulour maka sekolah telah turut ambil bagian dalam upaya pemerintah untuk mengatasi kepunahan bahasa Toulour sekaligus melestarikan bahasa Daerah sebagai kekayaan budaya bangsa sebagaimana yang diamanatkan oleh UU Negara RI No. 24 Tahun 2009.

Menyikapi berbagai permasalahan yang ada di sekolah-sekolah, maka UNIMA sebagai lembaga pendidikan yang selalu responsif terhadap berbagai permasalahan dan kebutuhan yang ada di tengah-tengah masyarakat, melalui lembaga Penelitian dan Pengabdian kepada Masyarakat bersama tim 
dosen yang ada di Fakultas Bahasa dan Seni (FBS), hendak melaksanakan suatu kegiatan pengabdian kepada masyarkat disekolahsekolah ini, dengan memprioritaskan dua kegiatan yang menjadi kebutuhan sekolah. Kegiatan pelatihan bahasa Toulour adalah wujud upaya UNIMA untuk merintis pembelajaran bahasa Toulour di sekolah, dengan harapan bahwa melalui pelatihan ini akan dihasilkan modul pembelajaran bahasa Toulour yang nanti akan dapat digunakan guru-guru. Sedangkan kegiatan perpustakaan dilaksanakan dengan maksud supaya sekolah memiliki perpustakaan yang memadai, dengan koleksi buku yang aktual dan relevan dengan kebutuhan anak. Dengan adanya penataan perpustakaan yang baik akan meningkatkan minat belajat siswa-siswa berkunjung dan membaca buku di perpustakaan. Dengan demikian perpustakaan akan dapat berfungsi sebagaimana yang diharapkan sebagai sarana untuk menunjang pencapaian tujuan belajar mengajar.

Berdasarkan latar belakang yang telah dikemukakan, maka kegiatan Pengabdian kepada masyarakat ini diberi judul: "Program Kemitraan Masyarakat (PKM) Sekolah Dasar di Desa Passo Kecamatan Kakas Barat Kabupaten Minahasa".

Permasalahan Mitra
Terdapat dua permasalahan prioritas, yaitu:

Belum terealisasinya pembelajaran bahasa Toulour yang sudah lama diprogramkan sebagai mata pelajaran muatan lokal, sebagai wujud kepedulian sekolah akan pelestarian bahasa Toulour, karena masih terkendala dengan tidak adanya guru dan tidak adanya modul/buku panduan.

SDN Inpres dan SD Katolik St. Theresya di Desa Passo kecamatan Kakas Barat belum memiliki perpustakaan yang memadai, baik dari segi koleksi buku, secara kualitas dan kuantitas. Akibatnya perpustakaan tidak digunakan dengan baik dan tidak berfungsi secara maksimal. Kunjungan ke perpustakaan hanya berkisar $10 / 15 \%$.

\section{SOLUSI DAN TARGET LUARAN}

\section{A. Solusi Yang Ditawarkan}

1. Melaksanakan kegiatan pelatihan bahasa Toulour bagi siswa-siswa di kedua sekolah Mitra, SDN Inpres dan SD Katolik St. Theresya. Kemampuan berbahasa Toulour yang hendak dilatihkan adalah mencakup semua aspek keterampilan berbahasa, yaitu keterampilan menyimak, keterampilan berbicara, keterampilan membaca, keterampilan menulis 
Jurnal ABDIMAS, Vol. 13, No. 1, April 2020

ISSN: 1979-0953 | e-ISSN: 2598-6066

yang semuanya masih dalam taraf sederhana dan disajikan secara integrasi. Materi pembelajaran akan disusun dalam sebuah modul pembelajaran.

2. Melaksanakan kegiatan penataan perpustakaan, yaitu dengan menata ruang perpustakaan menjadi menarik, nyaman, bersih dan indah. Selanjutnya akan dilakukan pengadaan/penambahan buku, yang disesuaikan dengan kebutuhan bagi para siswa. Jenis-jenis buku yang akandiadakan adalah buku pelajaran dan buku lainnya. Selain itu akan diadakan lomba baca teks berbahasa Toulour, pidato menggunakan bahasa Toulour, menyanyi lagu berbahasa Toulour yang teksnya akan disediakan di perpustakaan. Semua kegiatan ini diharapkan akan dapat meningkatkan minat berkunjung dan membaca diperpustakaan yang sebelumnya hanya $10-15 \%$ dapat meningkat menjadi 50-75\%.

\section{B. Rencana Target Luaran}

\begin{tabular}{|c|c|c|}
\hline No & Jenis Luaran & $\begin{array}{l}\text { Indikator } \\
\text { Capaian }\end{array}$ \\
\hline & Luaran Wajib & \\
\hline 1 & $\begin{array}{l}\text { Publikasi Ilmiah di Jurnal } \\
\text { ber ISSN/Prosiding }\end{array}$ & Terdaftar \\
\hline
\end{tabular}

\begin{tabular}{|l|l|l|}
\hline 2 & $\begin{array}{l}\text { Publikasi pada media } \\
\text { massa cetak, } \\
\text { online/repocitory PT }\end{array}$ & Terdaftar \\
\hline 3 & $\begin{array}{l}\text { Peningkatan daya saing } \\
\text { (peningkatan kualitas, } \\
\text { kuantitas serta nilai } \\
\text { tambah barang, jasa, } \\
\text { diversifikasi produk atau } \\
\text { sumber daya lain) }\end{array}$ & \\
\hline 4 & $\begin{array}{l}\text { Peningkatan penerapan } \\
\text { IPTEK di masyarakat } \\
\text { (mekanisasi, IT, dan } \\
\text { manajemen) }\end{array}$ & Penerapan \\
\hline 5 & $\begin{array}{l}\text { Perbaikan tata nilai } \\
\text { masyarakat (seni budaya, } \\
\text { sosial, politik, keamanan, } \\
\text { ketentraman, pendidikan, } \\
\text { kesehatan) }\end{array}$ & $\begin{array}{l}\text { Sudah } \\
\text { dilaksanakan }\end{array}$ \\
\hline 1 & $\begin{array}{l}\text { Luaran Tambahan } \\
\text { Internasional }\end{array}$ & \\
\hline 2 & $\begin{array}{l}\text { Jasa: rekayasa sosial, } \\
\text { metode atau sistem, } \\
\text { produk/barang }\end{array}$ & \\
\hline
\end{tabular}

\section{METODE PELAKSANAAN}

Metode yang digunakan dalam pelatihan bahasa Toulour adalah metode eklektik atau metode atau metode campuran dari beberapa metode pengajaran bahasa seperti metode terjemahan, metode langsung, metode mimikri dan beberapa metode pengajaran umum, seperti diskusi, tanya jawab dan penugasan. Metode eklektik ini berbasis pendekatan Kontekstual, pendekatan Komunikatif dan pendekatan Whole Language.

Ridwan (2011:4) menyatakan, pendekatan kontekstual adalah konsep pembelajaran yang mengaitkan materi ajar 
Jurnal ABDIMAS, Vol. 13, No. 1, April 2020

ISSN: 1979-0953 | e-ISSN: 2598-6066

dengan situasi dunia nyata siswa, agar siswa benar-benar dapat memahami dengan lebih baik apa yang dipelajarinya karena dekat dengan kesehariannya. Pendekatan komunikatif adalah pendekatan yang memandang bahasa sebagai sarana untuk berkomunikasi, bukan sebagai perangkat kaidah untuk dihafal. Dengan pendekatan komunikatif siswa diarahkan untuk aktif berpartisipasi dalam proses pembelajaran. Selanjutnya pendekatan whole language adalah pendekatan yang berlandaskan prinsip bahwa bahasa itu tidak terpisahpisah, tetapi utuh dan lengkap, dimana ketika berbicara orang akan mendengar, bahkan sekaligus juga dapat menulis dan membaca. Dengan pendekatan whole language semua keterampilan berbahasa diajarkan secara terpadu atau terintegrasi. Sarana untuk mengikat keterpaduan ini adalah tema. Dengan satu tema keempat ketrampilan diajarkan secara terintegrasi. Karena itu materi pelatihan bahasa ini disusun secara tematik.

Kegiatan penataan perpustakaan dilaksanakan dengan melibatkan kepala sekolah dan guru-guru dalam menata ruang pperpustakaan dan mengatur tata letak buku-buku dengan rapih, indah dan menarik. Kegiatan lomba baca teks, pidato, lomba menyanyi dilakukan semeriah mungkin supaya memberi kesan yang baik bagi siswa tentang perpustakaan.

\begin{abstract}
Gambaran umum tentang keseluruhan kegiatan yang akan dilaksanakan adalah sebagai berikut:
\end{abstract}

1. Melakuka observasi dan analisis situasi sekolah mitra dalam hal ini tentang keadaan sekolah dan siswa-siswa terkait dengan bahasa Toulour

2. Menetapkan Sekolah-Sekolah Dasar yang akan menjadi mitra pelatihan yang semuanya berlokasi di desa Passo Kecamatan Kakas Barat

3. Membicarakan dengan pihak mitra tentang masalah yang menjadi prioritas yang ada pada siswa-siswa yang ada di dua sekolah mitra

4. Menyusun proposal kegiatan PKM Sekolah Dasar dan diusulkan ke Lembaga Penelitian dan Pengabdian Kepada Masyarakat UNIMA, Dana PNBP Tahun 2020

5. Jika proposal diterima maka akan ditindak lanjuti dengan pelaksanaan kegiatan pengabdian pada sekolahsekolah mitra yang dimulai dengan menyusun modul pembelajaran dan menyusun rencana kegiatan penataan perpustakaan. Penyususnan modul pelatihan bahasa Toulour akan melibatkan pakar bahasa Toulour serta tua-tua serta pemuka-pemuka masyarakat yang memiliki kemampuan berbahasa Toulour. Selanjutnya menyiapkan media pembelajaran, 
menyusun jadwal dan melaksanakan kegiatan sesuai dengan jadwal baik kegiatan pelatihan bahasa maupun kegiatan perpustakaan.

6. Membuat laporan kemajuan pelaksanaan kegiatan di tahapan tertentu sesuai aturan

7. Membuat laporan akhir/hasil kegiatan pelatihan

Secara garis besar tahap-tahap pelaksanaan kegiatan pengabdian ini disusun sebagai berikut:

- Penyusunan modul/materi ajar bahasa Toulour termasuk penyiapan media pembelajaran

- Persiapan teknis di lapangan, pembagian kelas (kelompok), pengaturan kelas dan lain-lain

- Pelaksanaan kegiatan pelatihan bahasa Toulour

- Melaksanakan kegiatan pendalaman atau pemantapan materi yang telah diajarkan/remedial

- Melaksanakan tes/evaluasi

- Pelaksanaan kegiatan penataan perpustakaan

- Menyusun dan memasukkan laporan kemajuan pelaksanaan kegiatan LPPM UNIMA

- Menyusun laporan akhir

- Memasukkan laporan akhir
Pelaksanaan kegiatan pengabdian ini tentunya akan berjalan dengan baik bila tim pelaksana dan juga mitra pelatihan dapat bekerja sama dengan baik. Karena itu sebagai wujud kontribusi siswa-siswa sebagai mitra dalam kegiatan ini, maka mereka diwajibkan selalu hadir dalam pelatihan sesuai jadwal yang disusun serta rajin dan serius mengerjakan tugas-tugas yang diberikan, tentunya selalu dalam arahan dan bimbingan tim pelaksana pelatihan.

\section{KELAYAKAN PERGURUAN TINGGI}

Universitas Negeri Manado (UNIMA) adalah Lembaga Pendidikan Tinggi yang telah berpengalaman melaksanakan Tri Dharma Perguruan Tinggi. Khusus untuk dharma pengabdian kepada Masyarakat, LPPM UNIMA secara berkelanjutan terus meningkatkan eksistensinya dengan berbagai kegiatan pengabdian baik yang didanai oleh PNBP Unima maupun DIKTI. Dari tahun ketahun terlihat adanya peningkatan anggaran dan karena itu makin banyak pula dosen yang terlibat dalam kegiatan pengabdian kepada masyarakat. Kinerja UNIMA melalui LPPM juga nampak dari meningkatkan kerja sama LPPM UNIMA dengan pemerintah Provinsi, Kabupaten/Kota di Sulawesi Utara. Didukung oleh tim dosen pelaksana yang memiliki kompetensi dibidang yang menjadi 
permasalahan dalam kegiatan ini dengan kualifikasi akademik masing-masing, maka kegiatan ini dipandang layak untuk dilaksanakan.

Beberapa pengabdian yang dilaksanakan oleh LPPM UNIMA pada satu tahun terakhir ini antara lain pelatihanpelatihan Bhasa untuk Turisme guna mendukung Manado sebagai kota Ekowisata, Penyuluhan-penyuluhan atau Sosialisasi tentang global warning, rekayasa dan budidaya tanaman, pelatihan untuk kuliner, pelatihan kewirausahaan, pelatihan bahasa, dan masih banyak lagi kegiatan pengabdian yang telah memberi kontribusi positif bagi peningkatan kehidupan masyarakat.

Tim pelaksana kegiatan pengabdian ini juga merasa terpanggil untuk menjawab kebutuhan dan permasalahan yang ada dimasyarakat, lebih khusus di desa Passo Kecamatan Kakas Barat, yang mebutuhkan pembelajaran bahasa Toulour dan juga penataan perpustakaan sekolah. Kepakaran yang dibutuhkan untuk mengatasi permasalahan mitra dalam pelatihan ini telah dimiliki oleh tim pelaksana. Ketua tim pelaksana memiliki kualifikasi akademik bidang pendidikan dan pengajaran bahasa sekaligus memiliki kualifikasi berbahasa Toulour secara aktif dan pasif. Anggota tim pelaksana memiliki kualifikasi bidang seni budaya. Untuk memperkuat tim pelaksana dalam kegiatan ini, terutama dlama penyusunan modul/materi pelatihan, akan dilibatkan pula nara sumber, pakar bahasa Toulour serta tua-tua masyarakat tutur bahasa Toulour yang memiliki pengetahuan dan kemampuan berbahasa Toulour yang baik, sebagai tenaga sukarela.

\section{HASIL DAN LUARAN YANG DICAPAI}

Bahasa memiliki peranan penting dalam kehidupan, di dalam kehidupan manusia tidak dapat dipisahkan dari bahasa. Karena dari bahasa manusia dapat mengkomunikasikan sesuatu dengan sesamanya sebagai bagian dari suatu proses interaksi sebagai mahkluk sosial yang selalu membutuhkan orang lain dari didalam kehidupan setiap hari. Hal tersebut sejalan dengan apa yang dikatakan oleh Samsuri (1981:1-3) bahwa, "Mungkin bahasa tidak perlu bagi kehidupan alam semesta ini, akan tetapi pastilah merupakan hal yang paling vital bagi kehidupan manusia. Bahasa tidak terpisahkan dari manusia dan mengikuti setiap pekerjaannya. Mulai saat bangun pagi sampai waktu istirahat makan, manusia tidak lepas dari pemakaian bahasa, malahan pada waktu tidurpun tidak jarang ia memakai bahasanya". Melalui bahasa dapat terjadi suatu komunikasi yang aktif antar manusia sehingga dapat menunjang suatu proses hubungan kerja sama di dalam berbagai bidang kehidupan manusia itu sendiri guna menunjang kelangsungan hidupnya. Dengan bahasa manusia dapat 
mengungkapkan buah pikiran, dan perasaan bahkan keinginannya kepada orang lain. Badudu (1996:3) mengatakan bahwa, "bahasa adalah alat penghubung, alat komunikasi diantara anggota masyrakat yitu individuindividu tadi sebagai manusia yang berpikir, merasa dan berkeinginan".

Menurut Keraf (1978:14) mengatakan "bahasa adalah alat komunikasi antara anggota masyarakat berupa lambang bunyi suara yang dihasilkan oleh alat ucap manusia “, sedangkan Samsuri (1983:4) mengungkapkan bahwa "bahasa adalah alat yang dipakai untuk membentuk pikiran dan perasaan, keinginan dan peraturanperaturan."

Dari beberapa pendapat para ahli di atas dapat disimpulkan bahwa bahasa merupakan suatu sarana komunikasi dalam menyampaikan informasi kepada setiap anggota masyarakat dalam bentuk bunyi atau suara yang mengandung makna sehingga dapat diterima oleh pendengar. Sehingga jelaslah bahwa dalam komunikasi manusia selalu menggunakan bahasa karena bahasa merupakan sarana yang penting dalam kehidupan manusia, sebab tanpa bahasa hilanglah semua bentuk kegiatan manusia.

\subsection{Pengertian Bahasa Daerah \\ Bahasa daerah adalah bahasa yang dituturkan di suatu wilayah dalam suatu negara kebangsaan, baik itu dalam daerah}

kecil atau daerah yang lebih luas. Halim (1984:67) mengatakan " bahasa daerah adalah bahasa yang memperkaya khazana budaya bangsa, menambaha perbendaharaan kosa kata bahasa Indonesia sedangkan bahasa Indonesia menjadi alat pemersatu antar daerah".

Pasal 1 angka 5 UU Nomor 24 Tahun 2009 tentang bendera, Bahasa, dan Lambang Negara serta lagu Kebangsaan. Bahasa daerah adalah bahasa yang digunakan secara turun-temurun oleh warga negara Indonesia di daerah-daerah di wilayah negara kesatuan Republik Indonesia.

Adapun ringkasan materi yang diajarkan kepada anak didik di kedua Sekolah Dasar tersebut yaitu: 
1. Teles

2. Makantar

3.Kumelang

4. Kuman

5. Nonot

6. Tumanem

7.Sumiwo

8.Teles

9. Selet

10. Kumemes

11. Kumelang

12.Pakyang

13. Kumantar

14.Tembo

15. Opo

16.Natas

17. M'bale

18. Mupuk

19. Sumigi

20. Rumun

21. Reges

22. Lingah

23.Lingkoi

24. Weru

25. Teles

26.Nyaku

27. Nonon

28. Tumanem

29. Kou

30. Kaampit

31. Ambone

32. Karot

33. Mok

34. Wuring

35. Puti

36. Wendu

37. Wesu

38. Huran

39. Tekel

40. Wuruk

41. Punti

42. Esa

43. Rua

44. Telu

45. Sera

46. Tou 'beli'

'bernyanyi'

'berjalan'

'makan'

'minum'

'tanam'

'masak'

'beli'

'selip'

'cuci baju'

'berjalan'

'kerja'

'bernyanyi'

'lihat'

'Tuhan'

'atas'

'rumah'

'panen'

'hormat'

'duduk'

'angin'

'telingah'

'kecil'

'baru'

'beli'

'saya'

'beri rasa

'tanam'

'anda'

'teman'

'ambil'

'garuk'

'cangkir'

'hitam'

'putih'

'lelah'

'kenyang'

'hujan'

'tidur'

'basah'

'pisang'

'satu'

'dua'

'tiga'

'ikan'

'orang'
47. Asuu

48. Repet

49. Wengi

50 . Woondo

51. Lawas

52. Mberen

53. Mbuuk

54. Mokan

55. Mbawa

56. Lumeong

57.Lila

58. Ambon

59. Weru

60. Sera

61. Oki

62.Kiok

63. Mahame

64. Tumekel

65. Mbengi mo

66.Kaleong

67.Sua

makan'

68. Tia

69. Lambung

70. Mbuuk

71. Mbale

72.Mbanua

73. Rumumun

74. Makantar

75. Munte

76. Loho

77. Bekerja

78. Asu

79. Punti

80. Kaampit

81. Sero

82. Sumero

83.Inta

84. linga

85.Nae

86.Lawas

87.Ngaran

88. Lua

89. Toro

90.Rano

91. Passo 'besok'

'cepat'

'malam'

'besok'

'tangan'

'mata'

'rambut'

'nanti'

'bawah'

'bermain'

'bicara'

'ambil'

'baru'

'ikan'

'kecil'

'kasihan'

'menanggis'

'sedang tidur'

'sudah makam'

'teman bermain'

'memberi

'tidak'

'baju'

'rambut'

'rumah'

'daerah'

'duduk'

'menyanyi'

'lemon'

'lihat'

'mapakyang'

'anjing'

'pisang'

'teman'

'cari'

'mencari'

'ayo'

'telingah'

'kaki'

'tangan'

'nama'

'munta'

'bisa'

'panas' 
Jurnal ABDIMAS, Vol. 13, No. 1, April 2020

ISSN: 1979-0953 | e-ISSN: 2598-6066

\begin{tabular}{|c|c|c|c|}
\hline 92. Nemel & 'dingin' & 135. Mahai & 'datang' \\
\hline 93.Matua & 'tua' & \multirow{2}{*}{\multicolumn{2}{|c|}{ 'panggilan (untuk anak }} \\
\hline 94. Geleos & 'baik' & & \\
\hline 95.Kuman & 'makan' & 137. Wewene & 'perempuan' \\
\hline 96. Sumakit & 'sakit' & 138. Tuama & 'laki-laki' \\
\hline 97. Poot & 'perut' & 139. Wisa & 'dimana' \\
\hline 98. Rokos & 'kepala' & 140. Selok & 'salah’ \\
\hline 100.Wehan & 'beri' & 141.Maapumo & 'sudah habis' \\
\hline 101.Huran & 'hujan' & 142.Maharem & 'lapar' \\
\hline 102.Loyot & 'burung & 143. Mareomo & 'sudah haus' \\
\hline \multicolumn{2}{|l|}{ manguni' } & 144.Mareng & 'pulang' \\
\hline 103. Loit & 'Uang' & \multicolumn{2}{|l|}{ 145. Sia } \\
\hline 104. Watu & 'batu' & 146.Gofela & 'nyamuk' \\
\hline 105. Pinawetengan & 'pembagian' & \multicolumn{2}{|l|}{ 147.Mangge } \\
\hline 106. Turu & 'tunjuk' & 148.Tumuru & 'tunjuk' \\
\hline 107. Ndai & 'tidak' & \multicolumn{2}{|l|}{ 149. Tiamo } \\
\hline 108.Leos & 'baik' & \multicolumn{2}{|l|}{ 150. Tia } \\
\hline 109.Kumaweng & 'kawin' & \multicolumn{2}{|l|}{ 151. Wangun } \\
\hline 110. Wendu & 'Lelah' & \multicolumn{2}{|l|}{ 152. Nipeng } \\
\hline 111. Weru & 'baru' & \multicolumn{2}{|l|}{ 153. Kanawu } \\
\hline 112. La'ut & 'terlepas' & \multicolumn{2}{|l|}{ 154. Wewenw oki } \\
\hline 113. Tou & 'orang' & \multicolumn{2}{|l|}{ perempuan’ } \\
\hline 114. Nanam & 'rasa' & 155.Tumeles & 'membeli' \\
\hline 115. Lana & 'minyak' & 156. Kawanua & 'satu daerah' \\
\hline 116. Towa & 'panggil' & 157.Kagenang & 'terkenang' \\
\hline 117. Towaku & 'rokok' & 158. Umbaya & 'semua' \\
\hline 118. Tumendas & 'kurus' & 159.Kaleong & 'teman bermain' \\
\hline \multicolumn{2}{|c|}{ 119.Turu 'memperlihatkan' } & 160.Kekelangan & 'tempat jalan' \\
\hline 120. Mate & 'meninggal' & \multicolumn{2}{|l|}{ 161.Tuussen } \\
\hline 121. Kaput & 'singkong' & \multicolumn{2}{|c|}{ 'memperhatikan' } \\
\hline 122. Solo & 'lampu' & 162.Leleongan & 'mainan' \\
\hline 123. Towa & 'panggil' & 163. Sumaru & 'menghadap' \\
\hline 124.Koyawas & 'jambu' & 164. Endo & 'matahari' \\
\hline 125. Kela & 'luka' & 165.Sumigi & 'hormat' \\
\hline 126. Mairang & 'malu' & 166. Rumendai & 'siap' \\
\hline 127. Weta & 'kasihan' & 167.Tumbalen & 'Tabrak' \\
\hline 128. Wuter & 'berat' & & \\
\hline 129.mata pe & 'masih mentah' & 168. Masaruan & 'berhadapan' \\
\hline 130.Matokol & 'bertengkar' & 169.Rumamba & 'naik rumah \\
\hline \multicolumn{2}{|c|}{ 131. Matombol-tombolen } & \multicolumn{2}{|l|}{ baru' } \\
\hline \multicolumn{2}{|c|}{ 'saling mendorong (untuk } & 170. Miara & 'pelihara' \\
\hline \multicolumn{2}{|l|}{ kemajuan) } & 171. Mikir-mikiren & 'Berpikir' \\
\hline \multicolumn{2}{|c|}{ 132. Malingah-lingaan } & 172.Sumengkot & 'berangkat' \\
\hline \multicolumn{2}{|c|}{ 'saling mendengarkan' } & 178. Kan & 'nasi' \\
\hline 133. Upus & 'sayang' & 179.Sesepunan & 'hidung' \\
\hline 134. Magalo & 'marah' & 180. Numa & 'Kebun' \\
\hline
\end{tabular}




$\begin{array}{ll}\text { 181. Kawisa } & \text { 'kapan' } \\ \text { 182. Turu } & \text { 'tunjuk' } \\ \text { 183. Koatan } & \text { 'kuat' } \\ \text { 184. Wana Lalan } & \text { 'di jalan' } \\ \text { 185. Toro } & \text { 'bisa' } \\ \text { 186. Sawel } & \text { 'ganti' } \\ \text { 187. Rou } & \text { 'jauh' } \\ \text { 188. leleongan } & \text { 'mainan' } \\ \text { 189. Nisea } & \text { 'mereka' } \\ \text { 190. Nesem } & \text { 'asam' } \\ \text { 191. Nikoo } & \text { 'engkau' } \\ \text { 192. Nisia } & \text { 'dia' } \\ \text { 194. Rintek } & \text { 'halus' } \\ \text { 195. Selok } & \text { 'salah' } \\ \text { 196. Ka'a } & \text { 'sebab' } \\ \text { 197. Waya } & \text { 'semua' } \\ \text { 198.Edo } & \text { 'ambil' } \\ \text { 199.Sumela } & \text { 'akan menjadi } \\ \text { besar' } & \\ \text { 200.Wui } & \text { 'bertanya' }\end{array}$

\section{3 . Teknik Pemberian Materi}

Pertama materi diberikan dengan metode ceramah, menunjukkan gambargambar yang sesuai dengan arti yang akan dipelajari, kemudian diberikan kesempatan selama 30 menit siswa menghafal dengan sendirinya, dan selanjutnya siswa diberi kesempatan untuk menemukan gambar yang disebutkan guru secara bergantian. Walaupun hanya melalui Zoom oleh karena pandemi sehingga tidak bisa tatap muka secara langsung tapi terlihat antusias siswa dalam belajar bahasa Daerah.

Pembelajaran tentang bahasa daerah perlu digalakkan terus karena semakin hari penggunaan bahasa daerah tergeser oleh penggunaan bahasa Indonesia maupun bahasa Melayu. Oleh karena itu perlu upaya untuk

mempertahankan bahasa daerah agar tidak mengalami kepunahan. Pembelajaran melalui PKM ini dapat dijadikan bahan acuan bagi kemungkinan pembelajaran bahasa Toulour sebagai muatan lokal di Sulawesi Utara khususnya Minahasa

\section{KESIMPULAN DAN SARAN}

\section{A. Kesimpulan}

- Kegiatan pengabdian pada masyarakat dengan Judul PKM Sekolah Dasar di Desa Passo Kecamatan Kakas telah dilaksanakan dengan baik.

- Pelaksanaan pelatihan ini telah mencapai tujuan yang direncanakan karena semua peserta dapat menguasai dan menggunakan bahasa Tolour secara sederhana dan penataan kembali perpustakaan sekolah telah dilaksanakan dengan baik.

\section{B. Saran}

Dengan melihat keberhasilan yang diperoleh serta animo peserta didik maka disarankan agar kegiatan pengabdian pada masyarakat dalam bentuk pelatihan berupa kursus singkat seperti ini perlu dilanjutkan baik pada lokasi yang sama maupun pada lokasi yang lain dengan topik/materi yang berkelanjutan (Bahasa Tolour) ataupun bahasa Daerah lainny

\section{DAFTAR PUSTAKA}




\section{Jurnal ABDIMAS, Vol. 13, No. 1, April 2020}

ISSN: 1979-0953 | e-ISSN: 2598-6066

Chaer, Abdul dan Leonie Agustina. Surakarta). Surakarta: MLI Komisariat

2010. Sosiolinguistik Pengenalan Awal

Jakarta: Rineka Cipta.

Gunawan, Asim. 2007. Dampak

Kepunahan Bahasa-Bahasa Daerah Terhadap

Nasionisme dan Nasionalisme:

Tinjauan Sosiologi (Makalah yang disajikan

dalam Kongres Linguistik Nasional ke-12 di
Surakarta.

Kemendikbud. 2011. Undang-Undang

Negara RI No. 24 Tahun 2009.

Jakarta: Badan Pengembangan dan

Pembinaan Bahasa

Ridwan, Sakura. 2011. Metodologi

Pembelajaran Bahasa. Yogyakarta: Kepel Press 